\title{
Grafos de visibilidade (VGA) como ferramenta auxiliar na análise de estudos de acessibilidade em ambientes escolares
}

\author{
Visibility charts (VGA) as an auxiliary tool in analyzing accessibility \\ studies in school environments
}

HILTON MESSIAS DE SOUTO FILHO
Mestrando, Universidade Federal da Paraíba - UFPB, messias.hilton.arqt@hotmail.com

ANGELINA DIAS LEÃO COSTA

Doutora, Universidade Federal da Paraíba - UFPB, angelinadlcosta@yahoo.com.br

NARAYANA BARRIOS MARINHO

Mestranda, Universidade Federal da Paraíba - UFPB, narabarrios@gmail.com

\begin{abstract}
RESUMO
Este artigo objetiva apresentar os resultados parciais de uma pesquisa de mestrado em andamento e visa entender as relações entre a acessibilidade, a educação inclusiva e a arquitetura escolar no âmbito de um programa governamental da Paraíba. A metodologia consiste em uma pesquisa bibliográfica sobre Educação Inclusiva, Acessibilidade e Sintaxe Espacial, e uma análise projetual do ambiente escolar através da Análise por grafos de visibilidade ( VGA), parte da Sintaxe Espacial, utilizando-se o programa computacional "Depthmap", por meio da interpretação de grafos de conectividade e isovistas, a fim de compreender como os usuários, principalmente as pessoas com deficiência, percebem o espaço e dele se apropriam. Esses grafos consideram as barreiras físicas e visuais existentes, sejam do meio urbano ou edificado, mostrando o nível de conexão e integração dos espaços. Como resultado, verificou-se que o ambiente escolar estudado é um ambiente conectado e de grande potencialidade espacial, pois o aluno, ao circular pela escola, tem melhor entendimento do espaço, com maior facilidade para se deslocar e percorrê-lo de modo autônomo. Logo, foi possível concluir que a VGA pode se mostrar como uma importante estratégia de análise, contribuindo positivamente nos estudos acerca da acessibilidade, principalmente a físico-espacial.
\end{abstract}

PALAVRAS-CHAVE: Arquitetura escolar; acessibilidade; VGA.

\section{ABSTRACT}

This article aims to present partial results of an ongoing master's researchand understand the relationship between accessibility, inclusive education and school architecture within the scope of a government program in Paraiba. The methodology consists of bibliographic research on inclusive education, accessibility and spatial syntax; and a design analysis in a school environment through the 


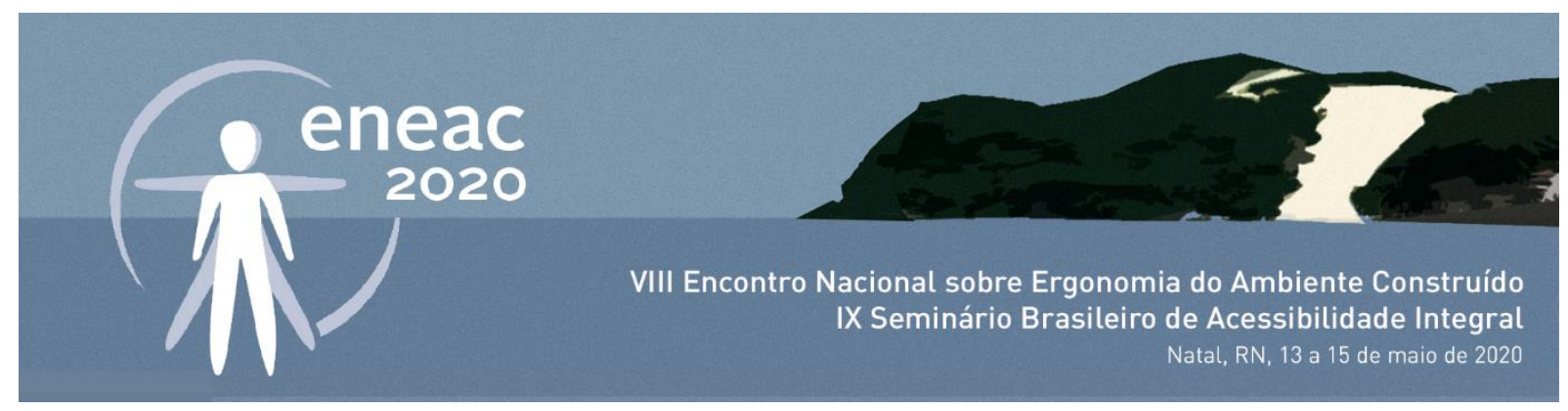

"Visibility Graph Analysis" (VGA), part of the spatial syntax, using the computer program "Depthmap", through the interpretation of connectivity and isovist graphs, in order to understand how the users, especially people with disabilities, perceive the space and appropriate it. These graphs consider the existing physical and visual barriers, whether urban or built, showing the level of connection and integration of spaces. As a result, it was found that the school environment studied is a connected environment and of great spatial potentiality, as the student, when circulating through the school, has a better understanding of the space, with greater ease to move and travel autonomously. Therefore, it was possible to conclude that VGA can prove to be an important analysis strategy, contributing positively to studies about accessibility, especially physical-spatial.

KEYWORDS: school architecture; accessibility; VGA.

\section{INTRODUÇÃO}

Este artigo apresenta parte dos resultados parciais de uma pesquisa de mestrado em andamento, que visa estudar as relações entre a acessibilidade, a educação inclusiva e a arquitetura escolar no âmbito do Programa Escolas Cidadãs Integrais (ECls), do Governo do Estado da Paraíba, com destaque às Escolas Cidadãs da Microrregião do Seridó Ocidental Paraibano, totalizando três escolas, a partir de um processo baseado em uma abordagem multimétodos.

Entendendo que a acessibilidade diz respeito à possibilidade de acesso, percepção e utilização de modo autônomo de espaços, edificações e do meio urbano (ABNT NBR 9050, 2015), e que a educação inclusiva visa eliminar as barreiras que dificultam o processo de aprendizagem de todos os estudantes, trazendo todas as pessoas à escola, com autonomia (MANTOAN, 2008; DELGADO, 2016), e, relacionando esses conceitos à arquitetura escolar, é possível propor estratégias, principalmente relacionadas à acessibilidade físico-espacial, para ambientes escolares verdadeiramente inclusivos.

Com relação ao Programa Escolas Cidadãs Integrais, esse é um projeto que visa estabelecer uma rede de escolas de educação integral na esfera estadual de ensino. Iniciado em 2016 com 8 escolas, para este ano de 2020, o Programa conta com um total de 229 escolas situadas em 150 municípios paraibanos, atendendo cerca de 80 mil alunos, de acordo com dados da Secretaria de Estado da Educação (SEE).

Nesse sentido, esta pesquisa considera que o ambiente escolar passa por um processo, desde a sua concepção, até o uso e apropriação do espaço pelo usuário (caracterizada na sua percepção), que compreende três dimensões distintas e subsequentes: a projetada, a construída e a percebida. Logo, buscou-se utilizar um conjunto de métodos, de modo que cada dimensão pudesse ser analisada de modo independente. Nas pesquisas por referências e trabalhos realizados acerca da acessibilidade no ambiente escolar, notou-se que são poucas as ferramentas metodológicas utilizadas, ficando às vezes muito restrito à aplicação de planilhas, na forma de checklists. Com isso, a fim de encontrar novas metodologias que possam auxiliar nesses estudos fez-se o uso da Sintaxe Espacial, entendendo seu grande potencial na avaliação não só de espaços urbanos, mas de ambientes construídos, a fim de possibilitar novas estratégias para o estudo da acessibilidade em ambientes escolares.

A partir do exposto, neste artigo serão apresentados os dados referentes a uma parte da primeira dimensão avaliada, a projetada, a partir de uma análise pela VGA, relacionando os resultados obtidos às questões voltadas à acessibilidade e à educação inclusiva. Como estudo de caso tomou-se como 


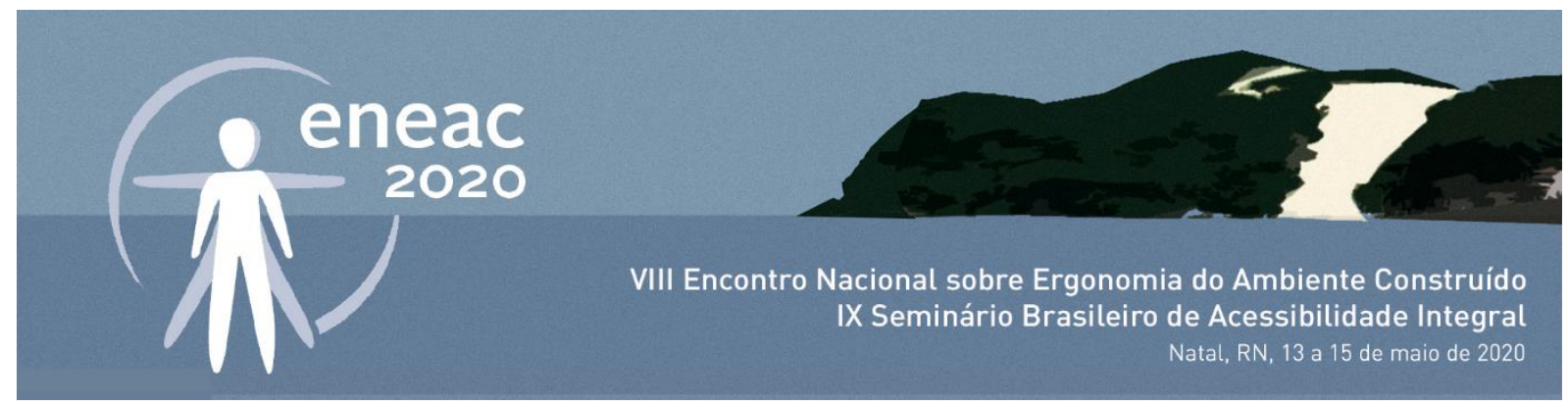

base os dados referentes a Escola Cidadã Integral Técnica Padre Jerônimo Lawen, no município de Santa Luzia, PB.

Logo, é preciso saber que Santa Luzia é um município da Microrregião do Seridó Ocidental Paraibano, que teve, para o ano de 2019, estimativa populacional de 15382 habitantes, destacando-se no estado no setor educacional obtendo o 19 melhor Índice de Desenvolvimento da Educação Básica (IDEB) para o ano de 2017. Já a ECIT Padre Jerônimo Lawen é uma edificação da década de 1970 que atende a alunos do ensino médio e médio profissionalizante, como também oferta educação de jovens e adultos, funcionando de modo integral das $7 \mathrm{~h}$ às $17 \mathrm{~h}$. A figura 1 apresenta essa escola.

Figura 1: Fotografia mostrando o acesso à Escola Padre Jerônimo Lawen

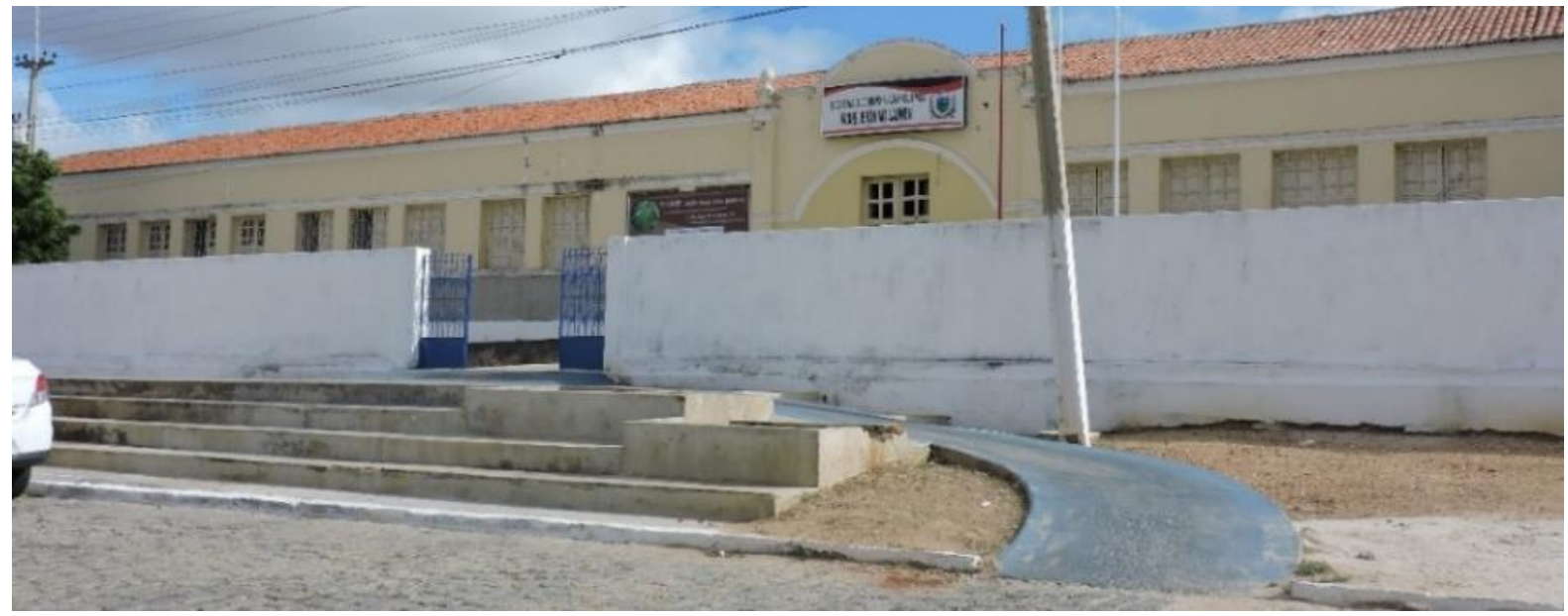

Fonte: Autores, 2019

No ano letivo de 2019 possuía 491 alunos matriculados no ensino médio e 92 na educação de jovens e adultos, contando ainda com 10 alunos da educação especial, que correspondem a 2,03\% do total de alunos. A figura 2 apresenta a planta baixa da escola setorizada.

Desse modo, este artigo tem como objetivo avaliar como a VGA pode contribuir nos estudos acerca das relações entre acessibilidade e educação inclusiva em ambiente escolares, por meio de estudo de caso com base em escola do Programa ECls do Governo da Paraíba.

Ao final pretende-se também responder a seguinte questão: como a VGA pode auxiliar nos estudos acerca das relações entre acessibilidade e educação inclusiva no ambiente escolar, no âmbito do Programa Escolas Cidadãs Integrais, do Governo da Paraíba?

Com isso, para uma melhor compreensão dos resultados serão apresentados a seguir os conceitos aqui elencados, acessibilidade e educação inclusiva, como também a Sintaxe Espacial com destaque à VGA, a fim de embasar a discussão que será gerada a partir dos resultados obtidos. 


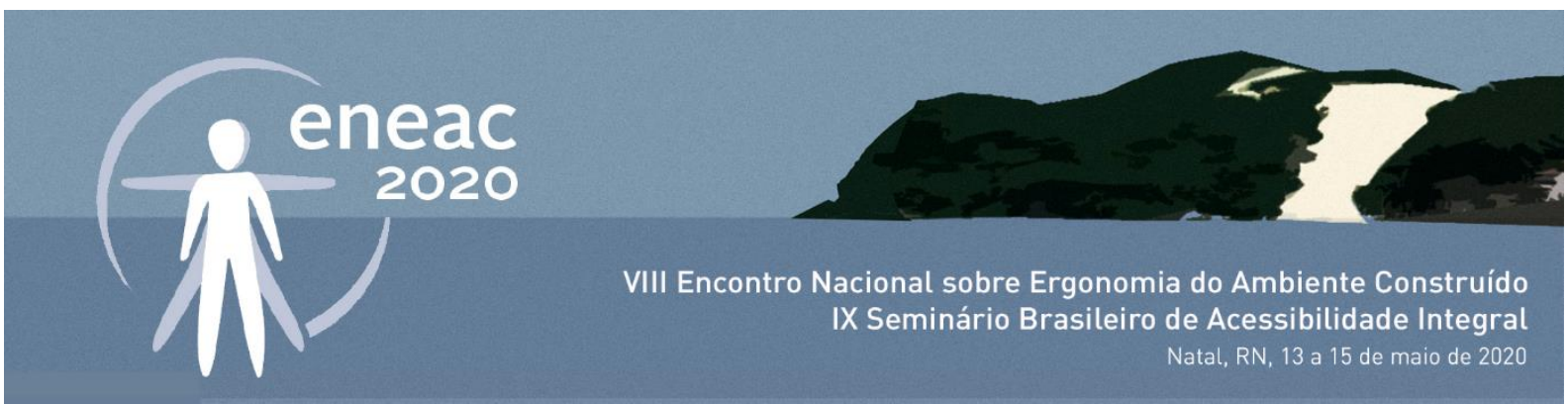

Figura 2: Planta baixa setorizada da ECIT Padre Jerônimo Lawen

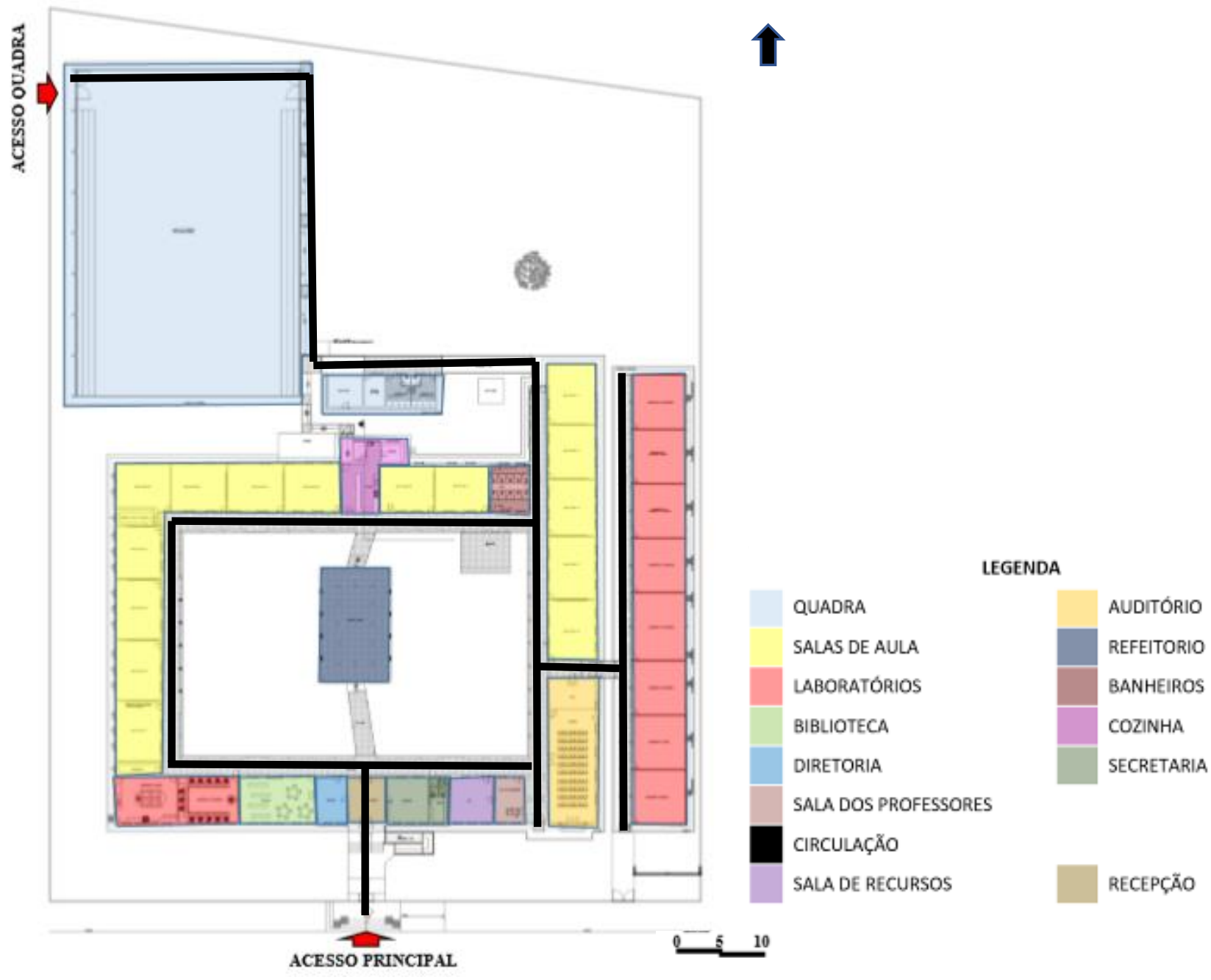

Fonte: Elaborado pelos autores com base em SUPLAN, 2019

\section{APORTE TEÓRICO}

\section{Acessibilidade e Desenho Universal}

A acessibilidade está ligada ao acesso, seja a espaços, a lugares ou simplesmente ao alcance de um objeto; mas também diz respeito à percepção e ao entendimento para utilização de modo autônomo desde espaços e edificações até o meio urbano. Segundo definição da Norma Brasileira de Acessibilidade, ABNT NBR 9050 (2015), a acessibilidade pode ser definida como:

Possibilidade e condição de alcance, percepção e entendimento para utilização, com segurança e autonomia, de espaços, mobiliários, equipamentos urbanos, edificações, transportes, informação e comunicação, inclusive seus sistemas e tecnologias, bem como outros serviços e instalações abertos ao 


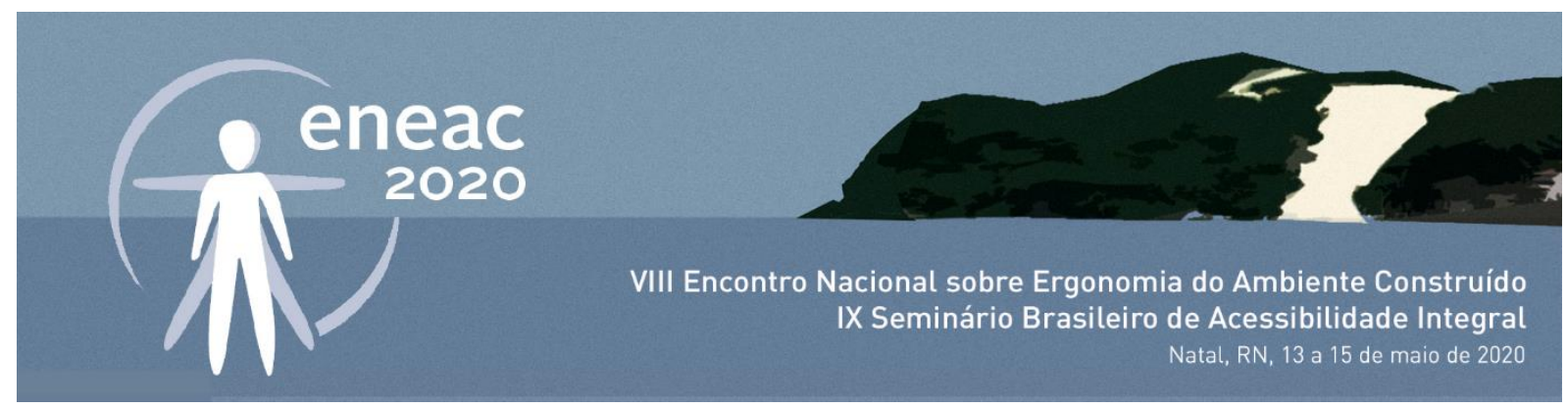

público, de uso público ou privado de uso coletivo, tanto na zona urbana como na rural, por pessoa com deficiência ou mobilidade reduzida. (ABNT NBR 9050, 2015, p. 16).

Assim, um objeto ou ambiente acessível é aquele que pode ser alcançado e usado por todos, de maneira segura e autônoma, refletindo na eficiência e satisfação pelas quais usuários específicos podem atingir metas específicas. Acessibilidade é um conceito bastante amplo, quando se considera a relação com a arquitetura e o urbanismo, esta vai desde questões ligadas ao ambiente edificado e suas relações com o entorno, passando por questões ligadas à mobilidade e à qualidade dos sistemas de transportes e vias de circulação urbana (ELALI, SÁ, 2012). Ao pensar-se no espaço, seja este edificado ou não, é preciso considerar a diversidade humana e o respeito às diferenças individuais. Logo, a acessibilidade ambiental é elemento essencial à inclusão (CALADO, 2006).

Junto ao conceito de acessibilidade vem o conceito de Desenho Universal, que surgiu entre os profissionais da área da arquitetura na Carolina do Norte, nos Estados Unidos. Tinha como objetivo desenvolver um projeto de ambientes que pudessem ser usados por todos, sem necessidade de adaptações ou projetos específicos para pessoas com deficiência. Foi criado, de fato, em 1987 pelo arquiteto Ron Mace, usuário de cadeira de rodas. Segundo Carletto e Cambiaghi (2007): "Desenho Universal é utilizado para descrever o conceito de projetar e construir produtos ou ambientes para serem utilizáveis, na maior medida possível, por todos. "

O Desenho Universal trata da universalização do acesso, ou seja, cria acessos ao universo abrangendo toda a diversidade humana. Ele é capaz de democratizar a vida das pessoas em diversos aspectos, indo desde a infraestrutura urbana, prédios públicos e casas até produtos de uso do dia-a-dia. Assim, não trata apenas de pessoas com deficiência e mobilidade reduzida, mas considera uma transformação na vida de toda a sociedade (CARLETTO, CAMBIAGHI, 2007).

O Desenho Universal deve beneficiar pessoas de todas as idades e condições físicas, sempre considerando todas as capacidades e habilidades, a fim de propiciar produtos que sejam utilizáveis por todos, sem necessariamente estarem destinados a uma parcela específica da população ou a pessoas com deficiência (STEINFELD, 2012).

Carletto e Cambiaghi (2007), deixam claro, a seguir, que todos necessitam do desenho universal, não sendo restrito a um grupo ou a pessoas com uma deficiência específica.

\footnotetext{
Ao longo de nossa vida mudamos nossas características e atividades. Quando somos crianças, nossas próprias dimensões nos impedem de alcançar ou manipular uma série de objetos, às vezes, por segurança, às vezes, porque a criança não foi pensada como usuário. Quando adultos, nos encontramos em inúmeras situações que dificultam, temporariamente, o nosso relacionamento com o ambiente - como gestação, fraturas, torcicolos, quando carregamos pacotes muito grandes ou pesados, entre outros. Ao alcançarmos mais idade, nossa força e resistência decrescem, os sentidos ficam menos aguçados e a memória decai. Também é possível, mesmo que não frequentemente, ao logo da vida, adquirir alguma deficiência, seja ela física, psíquica ou sensorial. (CARLETTO, CAMBIAGHI, 2007, p. 11).
}

Pode-se então dizer que o desenho universal significa superar o estigma da diferença com que tradicionalmente a pessoa com deficiência é tratada. O conceito supõe que a diversidade humana é então a regra, e não a exceção. Desse modo o desenho universal e a igualdade de oportunidades são os grandes ideais que mobilizam a luta pela acessibilidade (BENVEGNÚ, 2009). 


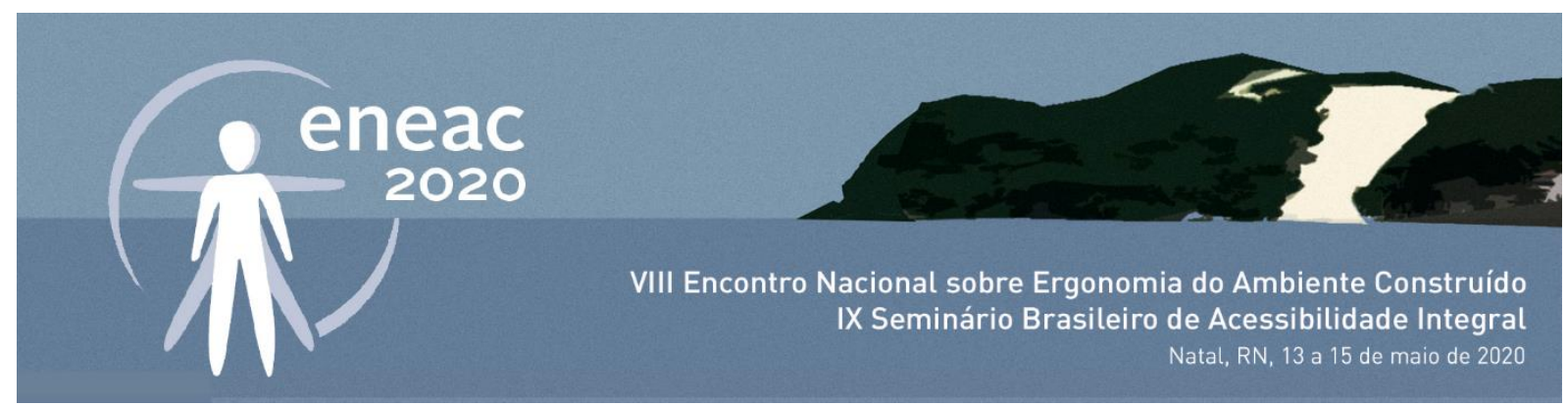

\section{Educação inclusiva}

Outro conceito importante é o de Educação Inclusiva. Segundo Delgado et al (2016), a inclusão escolar se caracteriza como um conjunto de processos orientados a fim de eliminar as barreiras que limitam a aprendizagem de todos os estudantes, visando aumentar a participação na cultura, nos currículos e nas comunidades das escolas. Para os autores, essas barreiras podem ser encontradas em todos os elementos e estruturas do sistema, como dentro das próprias escolas, na comunidade, nas políticas locais e nacionais.

Nesse sentido, de acordo com Mantoan (2008), a educação inclusiva se dá através de um processo que busca trazer todas as pessoas à escola, de modo que participem de forma efetiva. Ocorreu com a reestruturação do sistema de ensino e das práticas vivenciadas nas escolas, de maneira a atender a diversidade humana. Trata-se também de uma adequação do espaço físico do ambiente escolar, objetivando atender as diferentes capacidades funcionais da pessoa, as particularidades e peculiaridades no modo como se desenvolvem as diferentes atividades humanas.

Segundo afirma Mantoan (2003), a escola se "(...) entupiu do formalismo da racionalidade e cindiu-se em modalidades de ensino, tipos de serviço, grades curriculares, burocracia". A inclusão seria então a ruptura desse paradigma educacional. Para a autora, os sistemas educacionais estariam montados a partir de um pensamento que recorta a realidade, que permite a divisão dos alunos entre "normais" e deficientes, o ensino em regular e especial, os professores especialistas nessa e naquela deficiência. A educação inclusiva busca exatamente a ruptura dessa lógica separatista, os recursos da inclusão educacional devem então ser usados para facilitar a integração de todos os estudantes à escola, sempre em conjunto aos demais alunos. Nesse sentido, Mantoan (2003) entende que a inclusão total e irrestrita seria então uma oportunidade:

\footnotetext{
A inclusão total e irrestrita é uma oportunidade que temos para reverter a situação da maioria de nossas escolas, as quais atribuem aos alunos as deficiências que são do próprio ensino ministrado por elas sempre se avalia o que o aluno aprendeu, o que ele não sabe, mas raramente se analisa "o que" e "como" a escola ensina, de modo que os alunos não sejam penalizados pela repetência, evasão, discriminação, exclusão, enfim. (MANTOAN, 2003, p. 18).
}

Em contextos verdadeiramente inclusivos, nos quais os alunos são preparados para a cidadania visando seu pleno desenvolvimento humano, as crianças e adolescentes com deficiência não deveriam e não precisariam mais estar fora da classe regular de ensino infantil e fundamental, frequentando classes e escolas especiais (BRASIL, 2004).

A visão atual de educação inclusiva contrasta diretamente com a percepção tradicional que se tem do sistema de ensino brasileiro. É preciso reconhecer que historicamente o ensino regular foi excludente e o ensino especial discriminatório e segregador (BNEVEGNÚ, 2009). Assim:

A inclusão é uma inovação que implica um esforço de modernização e de reestruturação das condições atuais da maioria de nossas escolas (especialmente as de nível básico), ao assumirem que as dificuldades de alguns alunos não são apenas deles, mas resultam, em grande parte, do modo como o ensino é ministrado e de como a aprendizagem é concebida e avaliada (MANTOAN, 2003, p. 32). 


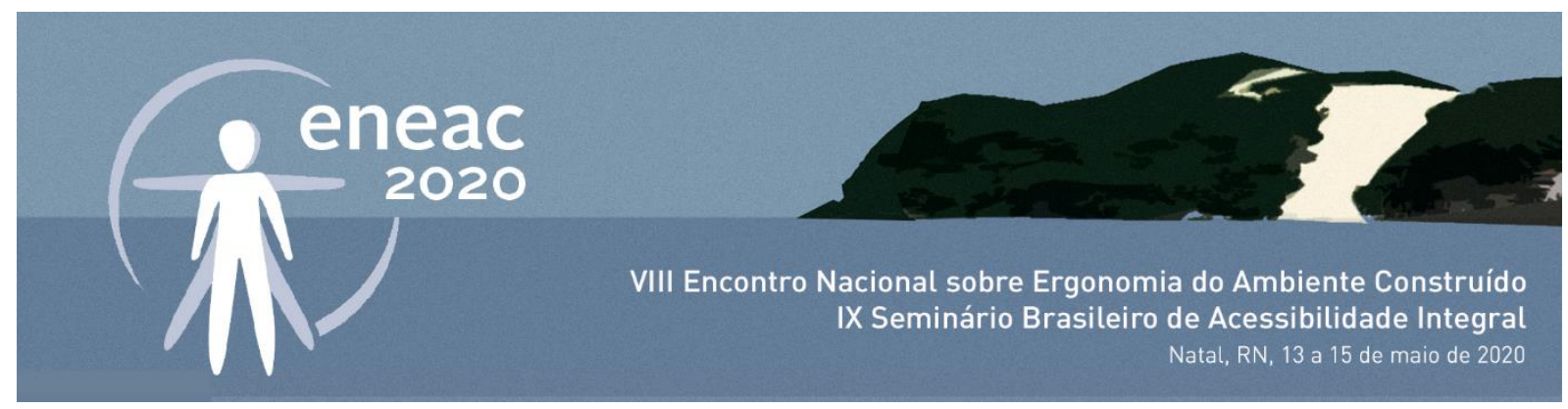

O futuro da escola inclusiva depende de uma expansão rápida de projetos verdadeiramente comprometidos a transformar a escola, de modo a adequar-se aos novos tempos, sempre no sentido de integrar, demonstrando a viabilidade da inclusão (MANTOAN, 2003).

\section{Sintaxe Espacial}

A Sintaxe Espacial, teoria apresentada por Hillier e Hanson (1984), é fundamentada em técnicas computacionais para analisar a configuração das cidades. Essa envolve desde técnicas de representação à quantificação e interpretação espacial (HILLIER et al, 1997).

De acordo com Gurgel (2018), através do uso da Sintaxe Espacial é possível estudar as relações que existem entre o espaço e as práticas socioculturais, através da representação e a quantificação da configuração espacial, compreendendo o espaço (urbano e edificado) como um sistema de permeabilidades e barreiras (áreas acessíveis ou não ao movimento) e de opacidades e transparências (aquilo que é ou não percebido pela nossa visão).

A metodologia surgiu a partir da observação dos aspectos físicos da cidade e sua integração com as interações sociais. Através da utilização desse método é possível averiguar o potencial que possui uma determinada estrutura espacial no que se refere à visibilidade, à geração de movimento, à acessibilidade e outros fatores que podem associar-se a essas propriedades (GURGEL, 2018).

Com isso, este artigo usará a VGA, com auxílio do programa Depthmap ${ }^{1}$.

\section{Análise por grafos de visibilidade (VGA)}

A VGA faz parte da Sintaxe Espacial e foi criada por Turner et al (2001) como uma alternativa metodológica para investigar as relações configuracionais da arquitetura. Funciona por meio de Isovistas ${ }^{2}$ e Grafos de Visibilidade ${ }^{3}$ que calculam métricas referentes aos campos visuais, abrindo um leque maior de possibilidade de análises espaciais.

\footnotetext{
${ }^{1}$ DepthmapX é uma plataforma de software multiplataforma para executar um conjunto de análises de redes espaciais projetadas para entender processos sociais dentro do ambiente construído. Trabalha em uma variedade de escalas, desde a construção, passando por pequenas cidades, até cidades ou estados inteiros. Em cada escala, o objetivo do software é produzir um mapa de elementos de espaço aberto, conectá-los através de algum relacionamento (por exemplo, intervisibilidade) e, em seguida, executar a análise gráfica. O objetivo da análise é derivar variáveis que possam ter significado social ou experimental. Fonte: < https://varoudis.github.io/depthmapX/ >. Acesso em 05 de março de 2020.
}

\footnotetext{
${ }^{2}$ A Isovista pode ser definida, de acordo com Benedikt (1979), como uma área no ambiente construído diretamente visível a partir de um determinado ponto. Por se tratar de um espaço ligado por um polígono fechado, possui propriedades geométricas, como área e perímetro. Dessa forma, a análise da configuração espacial deixa de ser linear (apenas comprimento) e passa a ser de superfície (largura e comprimento).
}

\footnotetext{
${ }^{3}$ A Análise de Grafos de Visibilidade (Visibility Graph Analysis - VGA, em inglês) é um método que permite analisar os potenciais de visibilidade de pontos no espaço aberto ou de um conjunto de espaços abertos (locais com permeabilidade visual). Diferente da Isovista, que é uma análise a partir de um ponto, as relações visuais no VGA são interpartes, ou seja, um espaço em relação ao outro (entre todos os pontos do espaço estudado).
} 


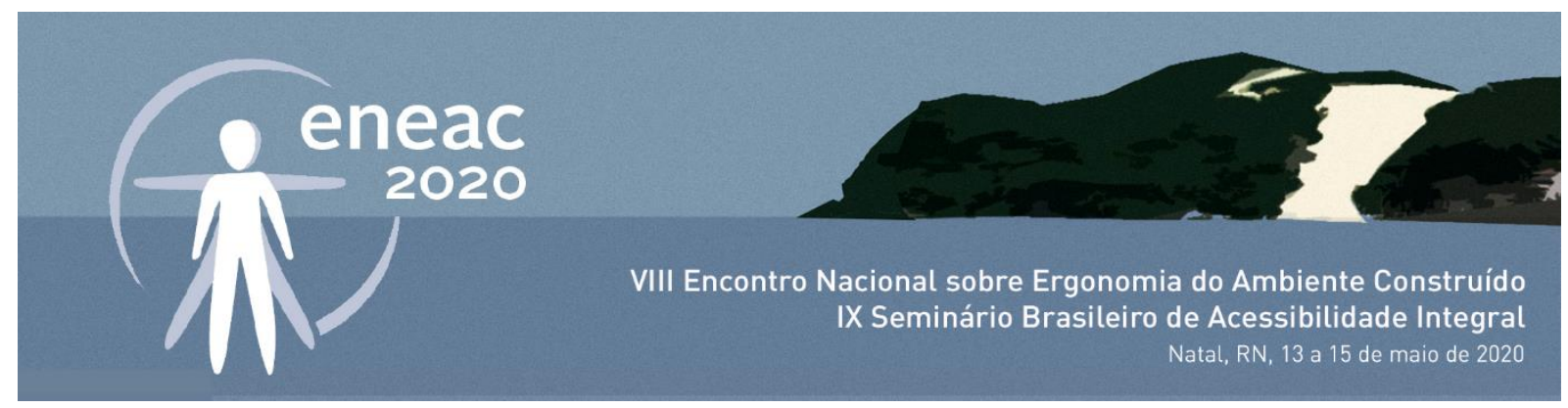

As análises sintáticas de visibilidade podem ser empregadas tanto para espaços arquitetônicos quanto para espaços urbanos. Dentre as possíveis linhas de trabalho que podem ser feitas com suporte de Isovistas e VGA, pode-se citar: Vitalidade de espaços públicos; segurança; co-presença; relações entre morfologia e uso do solo; fluxo de pessoas; quantidade e qualidade de atividades sociais; e simulações de projetos de arquitetura e urbanismo.

\section{METODOLOGIA}

Para atender os objetivos da dissertação foram definidos procedimentos metodológicos nos quais está incluída uma análise projetual de edifícios escolares a partir da VGA, por meio da interpretação de grafos de conectividade e isovistas, visando compreender como os usuários, principalmente as PcD (pessoas com deficiência) percebem o espaço e se apropriam do mesmo.

Com a elaboração dos grafos buscou-se entender as relações entre os diferentes espaços da escola, a fim de interpretar quais os principais mecanismos visuais que os alunos com deficiência utilizam para se orientar e como as barreiras físico-espaciais interferem negativamente nessa orientação.

Para a obtenção desses resultados foi necessário percorrer diferentes etapas: inicialmente foi realizado levantamento bibliográfico acerca das temáticas: acessibilidade, educação inclusiva e Sintaxe Espacial e VGA; em um segundo momento foram elaborados os grafos de conectividade e as isovistas com auxílio do programa Depthmap; e por último esses dados foram analisados relacionando os resultados à acessibilidade, educação inclusiva e à arquitetura escolar.

A ferramenta utilizada para criação dos grafos e isovistas é o programa Depthmap. Com os resultados obtidos foi possível observar as relações espaciais de visibilidade e conectividade, permitindo um entendimento da percepção que o usuário tem do espaço ao percorrê-lo e entender sua facilidade ou não de orientar-se.

Os grafos consideram as barreiras físicas e visuais existentes, seja do meio urbano ou edificado, mostrando o nível de conexão e integração daquele espaço. Há duas formas de considerar as barreiras do espaço físico na criação dos grafos: Isovistas na altura dos olhos e isovistas na altura do joelho, descritas a seguir.

Isovistas na Altura dos Olhos (Eye-Sovists): Isovistas que consideram apenas as barreiras ao campo de visão, como quarteirões, Edifícios, etc.

Isovistas na Altura dos Joelhos (Knee-Sovists): Isovistas que consideram barreiras ao movimento. Nesse caso, mesmo que haja uma barreira que possa ser visualizada através dela (canteiros, corpos d'água, mobiliário urbano, etc.), estas são representadas como um obstáculo ao campo visual. A figura 3 resume as etapas de trabalho. 


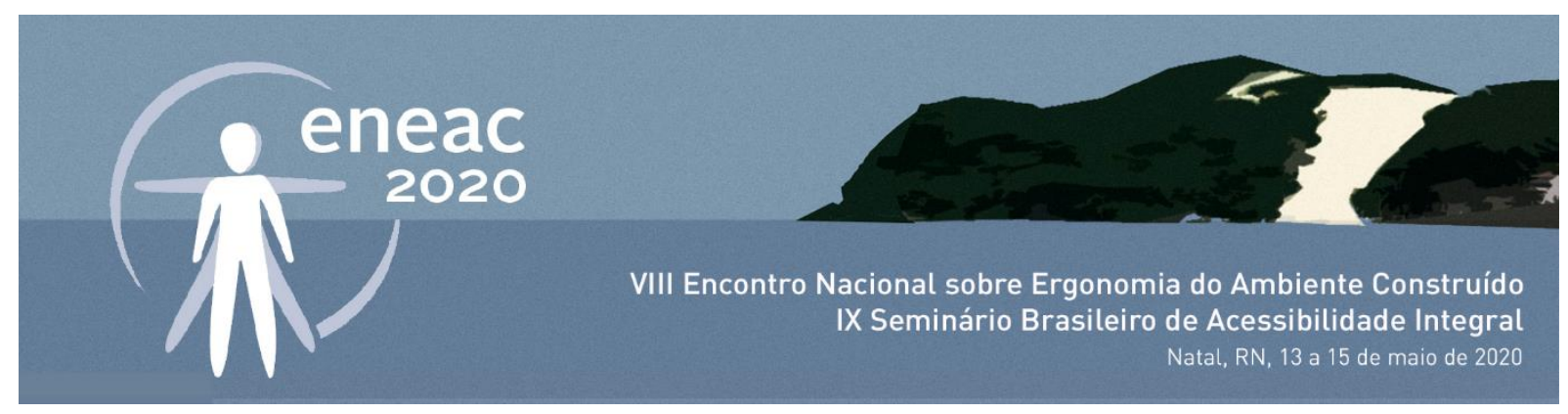

Figura 3: Sequência metodológica

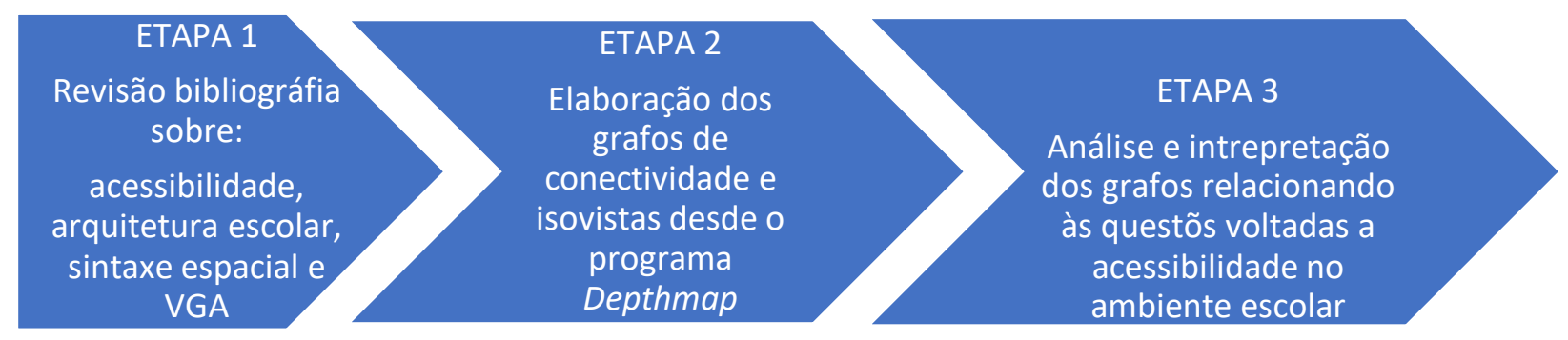

Fonte: Autores, 2020

\section{RESULTADOS}

Os resultados serão apresentados a partir de grafos de conectividade, a fim de entender as relações espaciais do sistema, considerando um campo de visão a partir de cinco metros de distância, de acordo com o que estabelece Jan Gehl no livro Cidades Para Pessoas (GEHL, 2013); e isovistas na altura dos olhos, de modo a compreender as relações visuais do espaço e a percepção do usuário ao percorrê-lo.

Os grafos de conectividade possuem uma gradação de cores, do roxo ao vermelho, funcionando como uma matriz de calor. Esses grafos interpretam cada ponto do espaço edificado com relação a todos os demais pontos, ou seja, quanto mais vermelho o ponto, mais conexão com o sistema espacial ele possui. Pode-se verificar, na figura 4 , um grafo de conectividade a partir de um campo visual na altura dos joelhos, ou seja, considerando principalmente as barreiras físicas, como escadas, rampas e degraus, entraves mais relevantes para a locomoção dos alunos com deficiência física. 

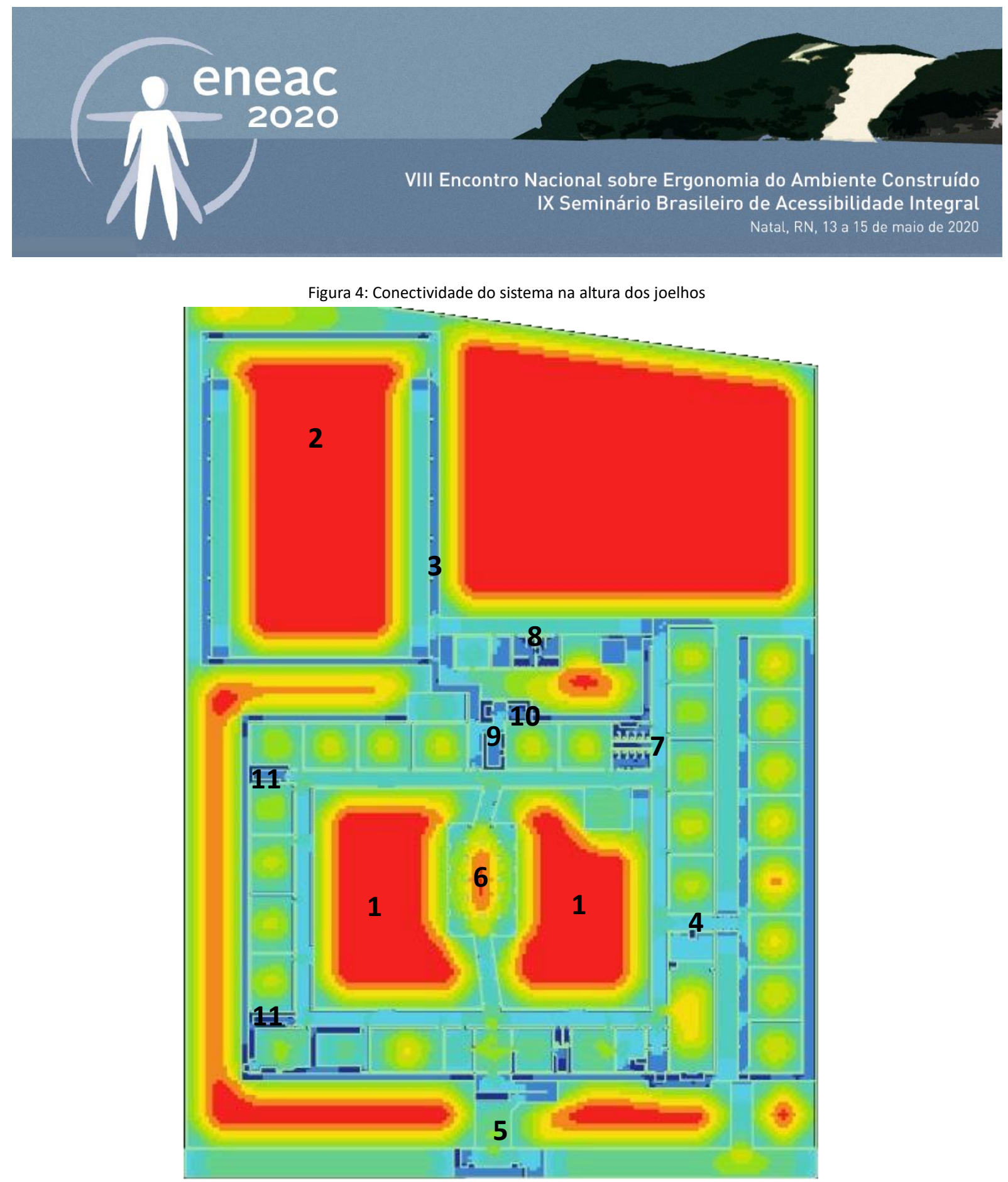

Fonte: Elaborado pelos autores com auxílio do programa Depthmap, 2019

A partir desse primeiro grafo é possível gerar uma série de interpretações sobre o projeto de arquitetura da ECIT Padre Jerônimo Lawen. A princípio, percebe-se que é um ambiente extremamente conectado, com destaque para o pátio central (1), que liga praticamente todos os espaços da escola. A quadra (2), por sua dimensão, também apresenta grande conexão. Isso reflete uma edificação de grande potencial, pois ao percorrer pela escola, o aluno terá maior entendimento do espaço, com maior facilidade para se deslocar de modo autônomo.

Alguns pontos mais escuros (azul), de menor conexão, são justamente as barreiras ao deslocamento, como degraus, diferenças de níveis entre ambientes, e até mesmo escadas e rampas. Podemos destacar a rampa de acesso à quadra (3), que aparece em cor fria, o acesso aos laboratórios (4), e as rampas e escadas de acesso ao edifício (5), tanto da calçada quanto da porta de entrada. 


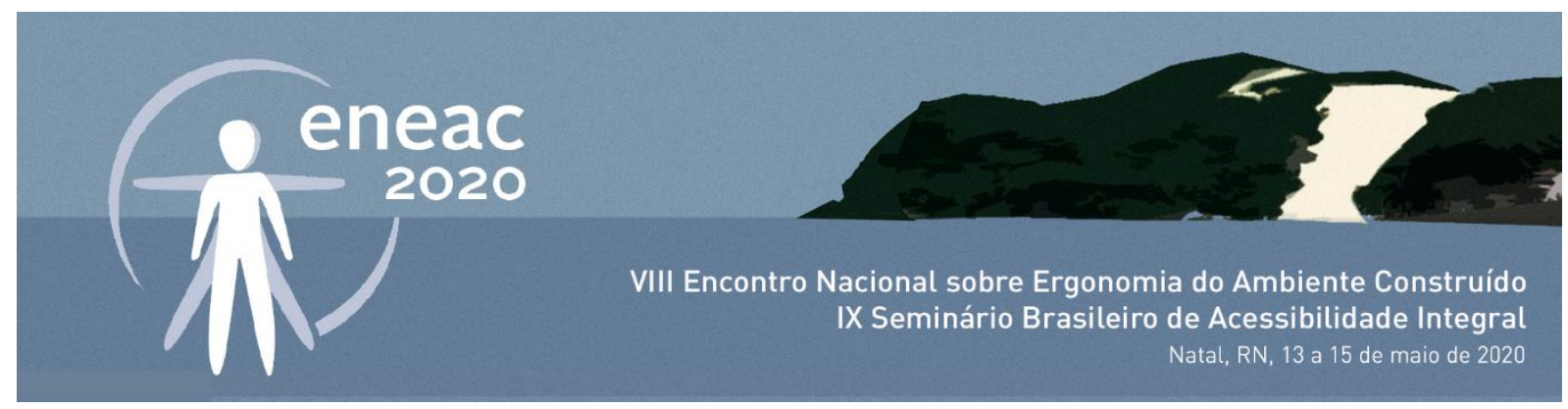

Também é interessante notar a quebra de calor que ocorre entre os dois lados do pátio, dividido pelo refeitório (6), que se torna uma barreira física e, em partes, visual. Nota-se um problema de conexão visto que esse se torna uma barreira, dificultado a passagem de um lado para o outro, e consequentemente afetando a autonomia do aluno, principalmente aquele que possui alguma deficiência física.

Os banheiros (7), por serem ambientes fechados e de menor tamanho, apresentam coloração mais fria, assim como os vestiários (8), a cozinha (9), a despensa (10) e os depósitos (11). O que, nesse caso, pode ser entendido como positivo, visto que são ambientes que requerem mais privacidade e menor fluxo de pessoas.

Já analisando o grafo que traz a conectividade a partir da altura dos olhos (considera apenas as barreiras visuais), da figura 5, confirma-se que é uma edificação de grande potencial. Quando eliminadas as barreiras físicas, a coloração se torna mais quente, indicando ainda mais grande conectividade e integração visual.

Nesse grafo, o pátio (1) possui maior interação como um todo, englobando o refeitório (6). Os corredores e salas indicam maior integração. Entende-se, nessa perspectiva, que a escola possui um espaço de fácil compreensão, proporcionando grande facilidade e autonomia para as pessoas que por ela circulam.

Contudo, não é uma situação que reflete a totalidade de possibilidades e de usuários. Pessoas com deficiência, seja física ou visual, e mobilidade reduzida, necessitam mecanismos adicionais para que tenham sua mobilidade de forma independente garantida.

Nesse grafo há pouca coloração fria, em tons de azul e roxo, que são justamente aqueles ambientes que assim devem ser mais restritos e de menor circulação, como já citado anteriormente. 

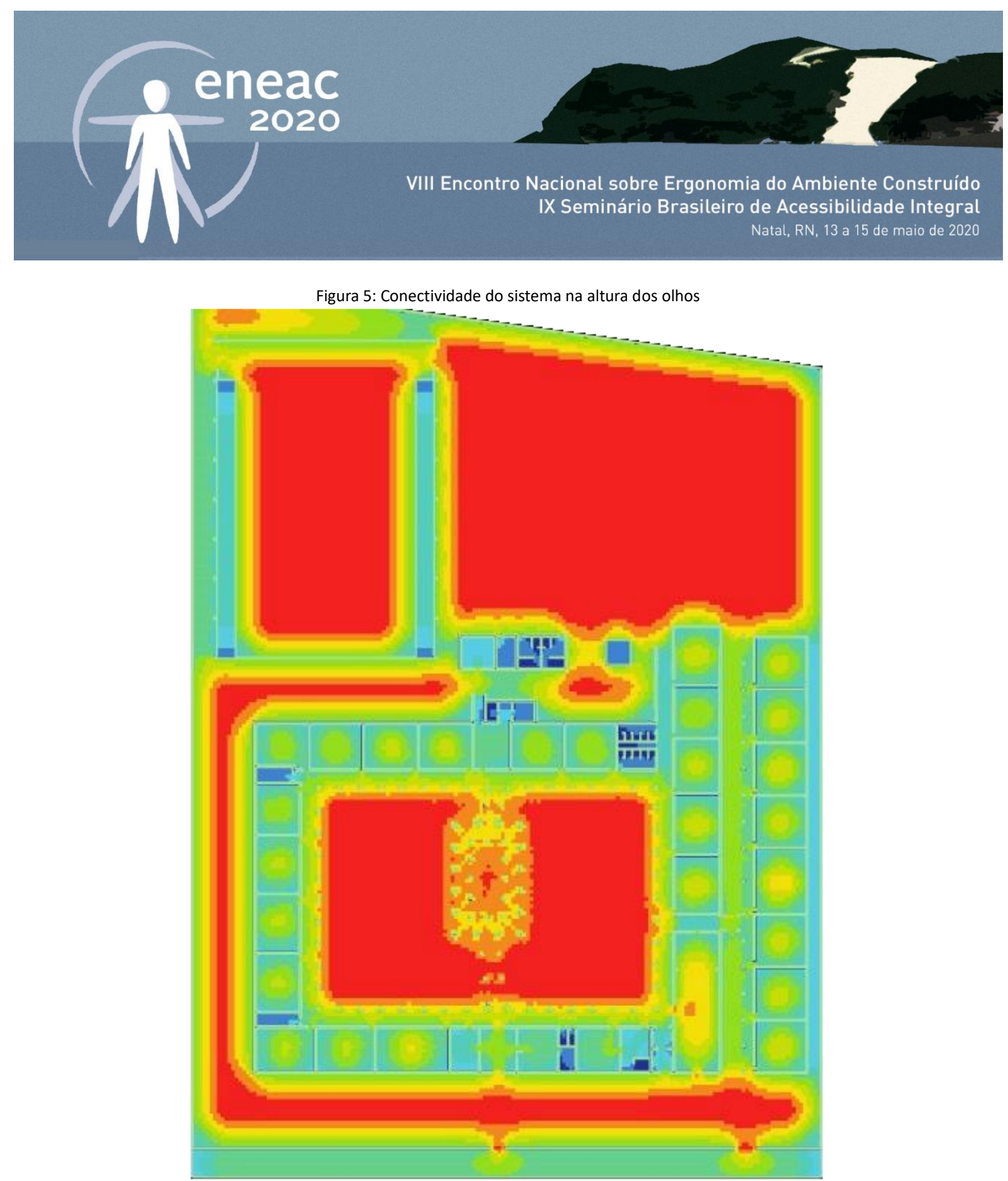

Fonte: Elaborado pelos autores com auxílio do programa Defphmap, 2019

O quadro 1 traz seis diferentes isovistas, cuidadosamente escolhidas desde pontos estratégicos, a partir de observação in loco em visita realizada à escola no mês de junho de 2019. Essas indicam o campo visual existente desde aquele local, considerando um raio de 360 .

Essas isovistas foram selecionadas principalmente para compreender como os usuários (seja aluno, funcionário, visitante etc.) que circulam pelo ambiente visualizam os principais ambientes, aqueles que concentram maior circulação e atividades da escola. 


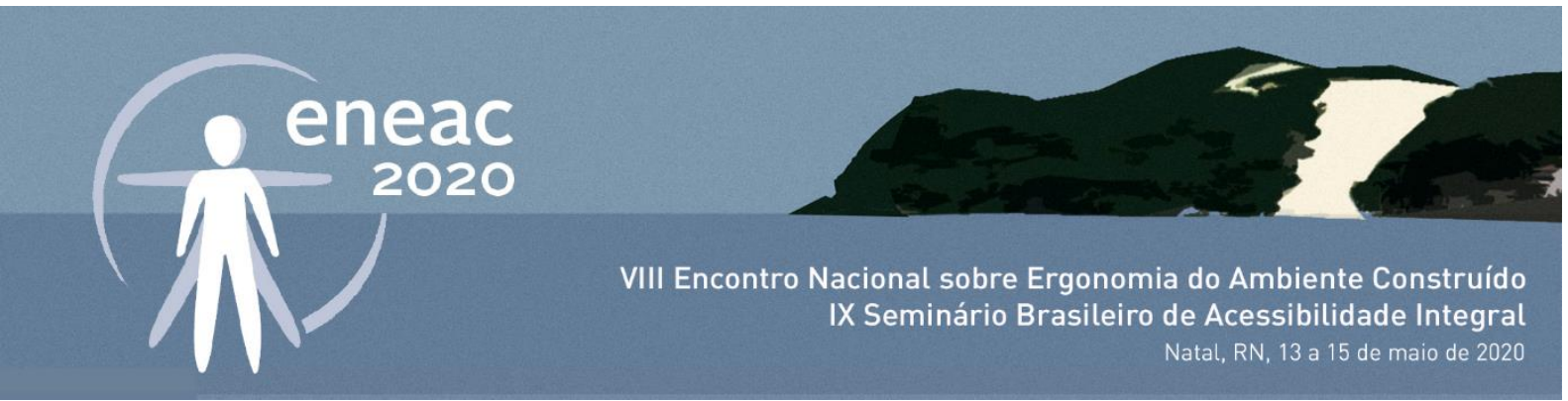

Quadro 1: Isovistas na altura dos olhos

\section{Visão desde o portão de entrada}

2. Visão da recepção para o pátio

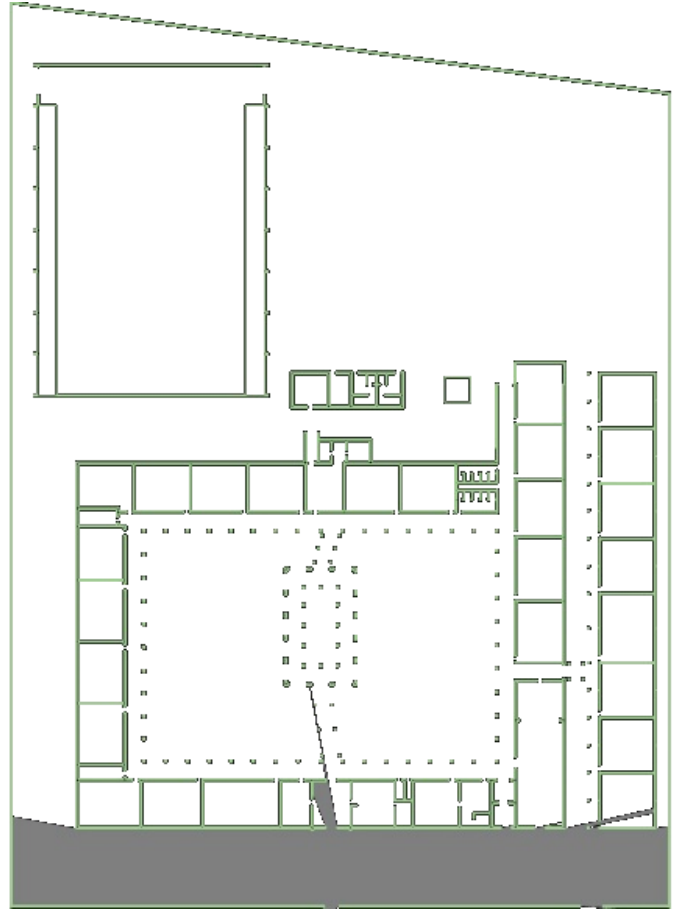

3. Visão do acesso aos laboratórios

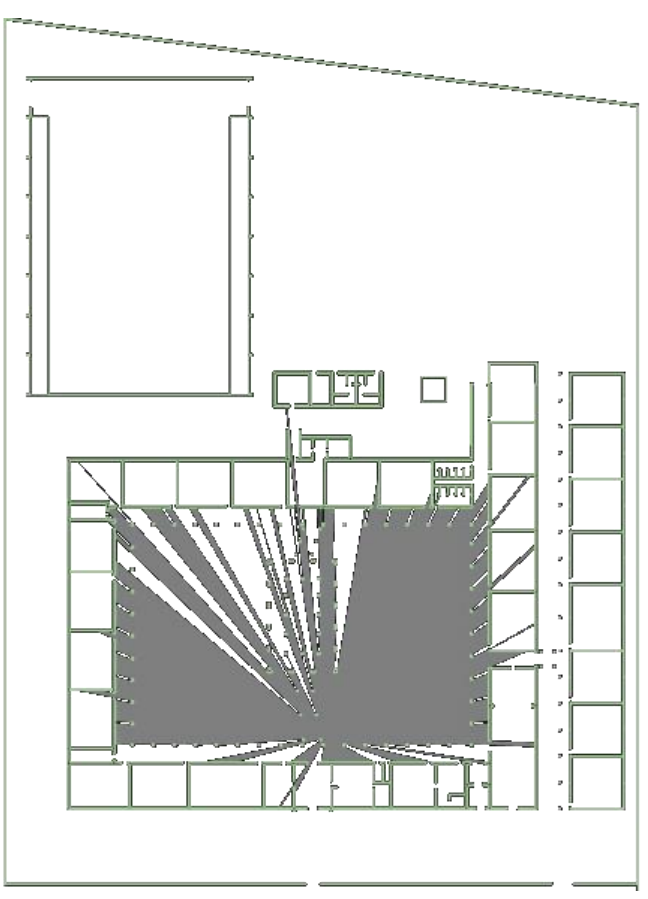

4. Visão do centro do refeitório
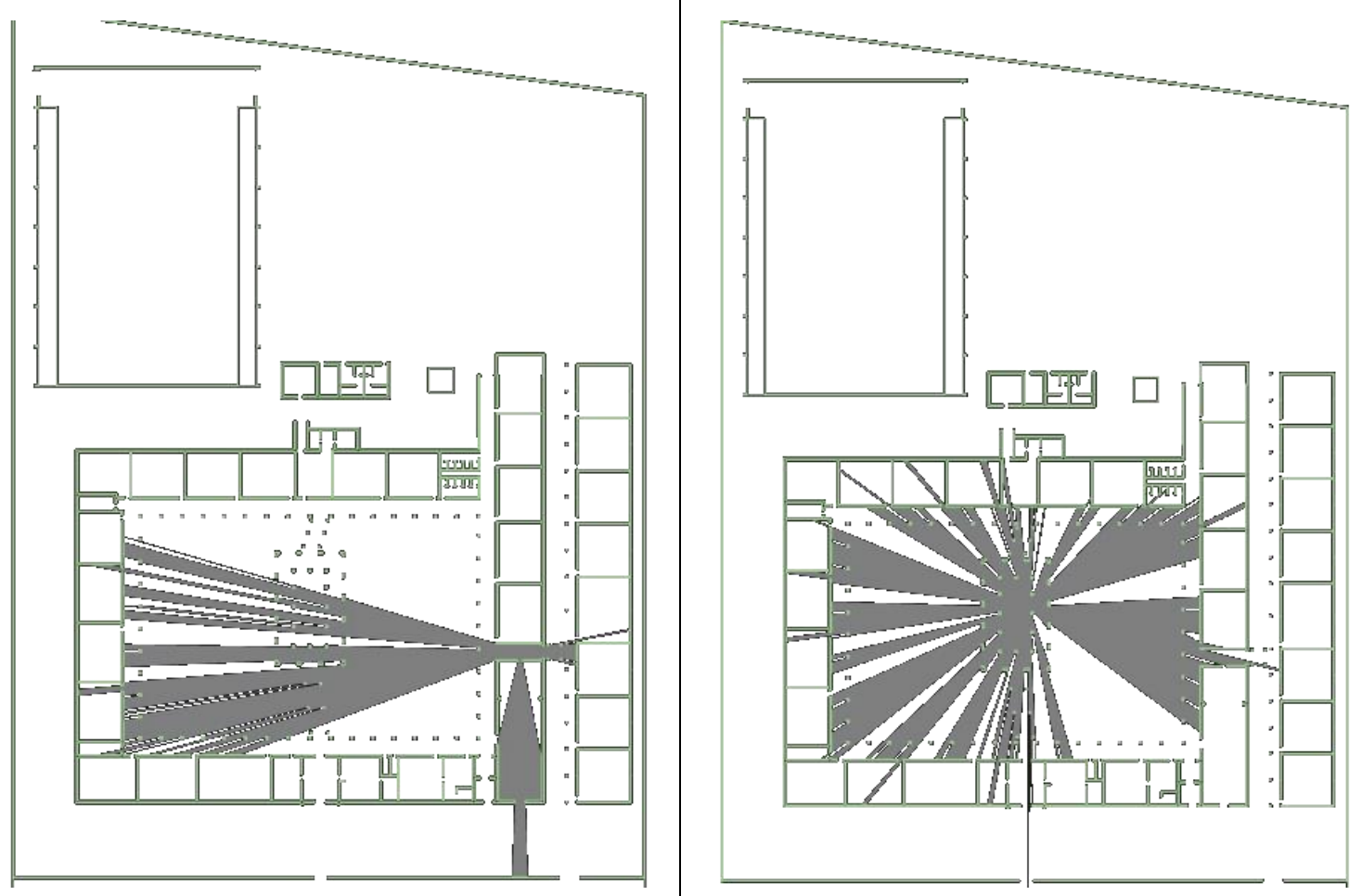

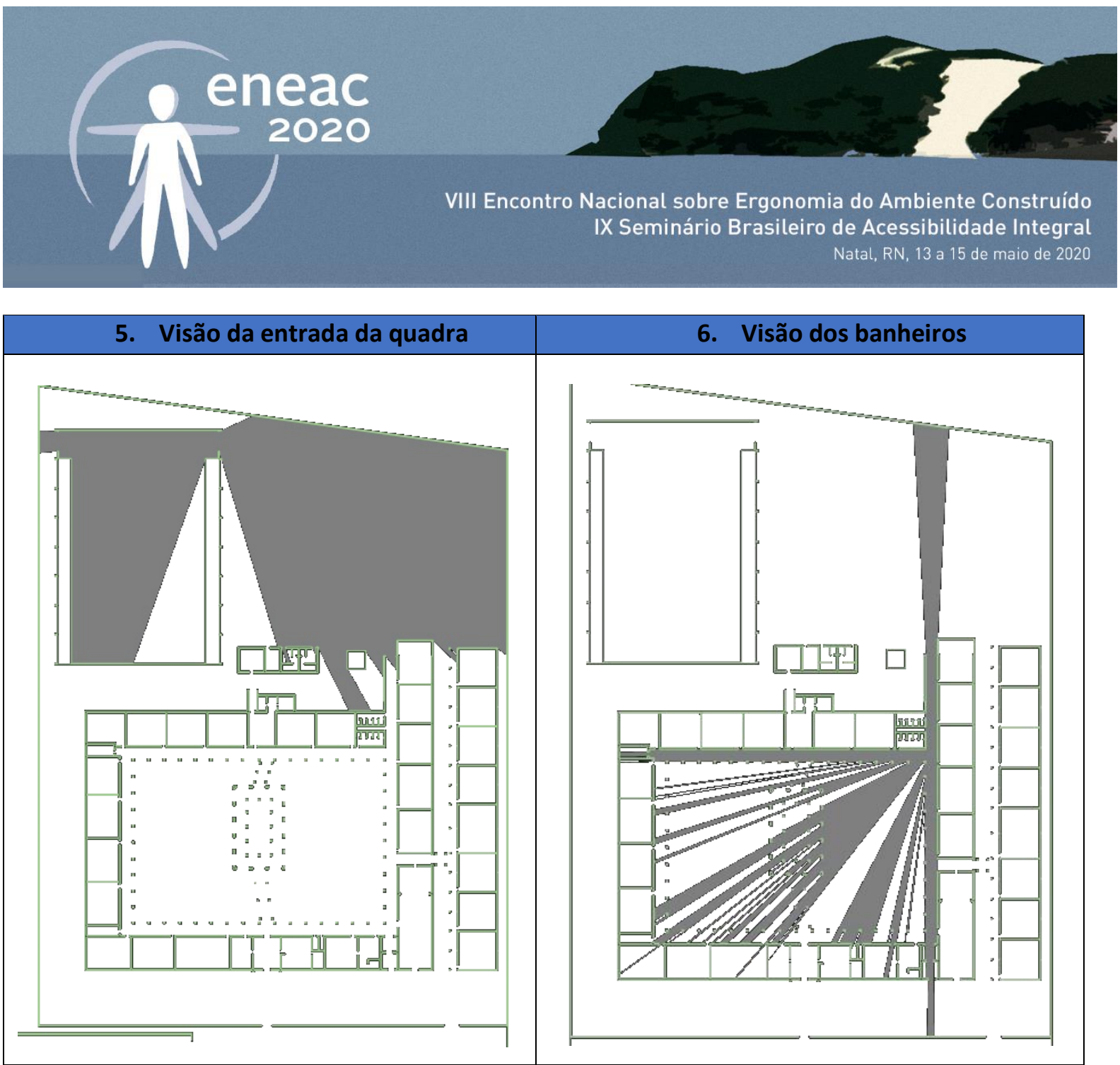

Fonte: Elaborado pelos autores com auxílio do programa Depthmap, 2019

A seguir ordenamos cada uma delas.

1. Na isovista pode-se observar a interpretação que se tem desde o portão, de onde é possível visualizar a fachada frontal e saber os caminhos que se pode percorrer. $O$ acesso pela porta principal se mostra de fácil compreensão.

2. Desde a recepção, acessando o corredor lateral ao pátio, tem-se um grande campo visual, podendo ser possível visualizar facilmente, salas de aula, refeitório e pátio. Desconsiderando as barreiras físicas, é um espaço de fácil entendimento.

3. Do centro do corredor que dá acesso aos laboratórios, é pequeno o campo visual para os mesmos, sendo maior com relação ao pátio; é necessário transpassá-lo para se ter um maior entendimento dessa parte da escola, principalmente os laboratórios que ficam mais ao fundo do corredor.

4. A partir do centro do refeitório, igualmente ao pátio, é possível ter uma visão geral da escola, sendo possível visualizar salas de aula, biblioteca, banheiros, cozinha, e o acesso da recepção. É o principal ponto de distribuição de fluxos.

5. Do portão de acesso à quadra, é possível ter uma visão geral desta, entender por onde se deve percorrer para acessar arquibancadas, de modo autônomo, por exemplo. Também há um amplo campo visual de toda área externa vazia da escola, dos vestiários e do acesso externo desde o corredor que vem do pátio. 


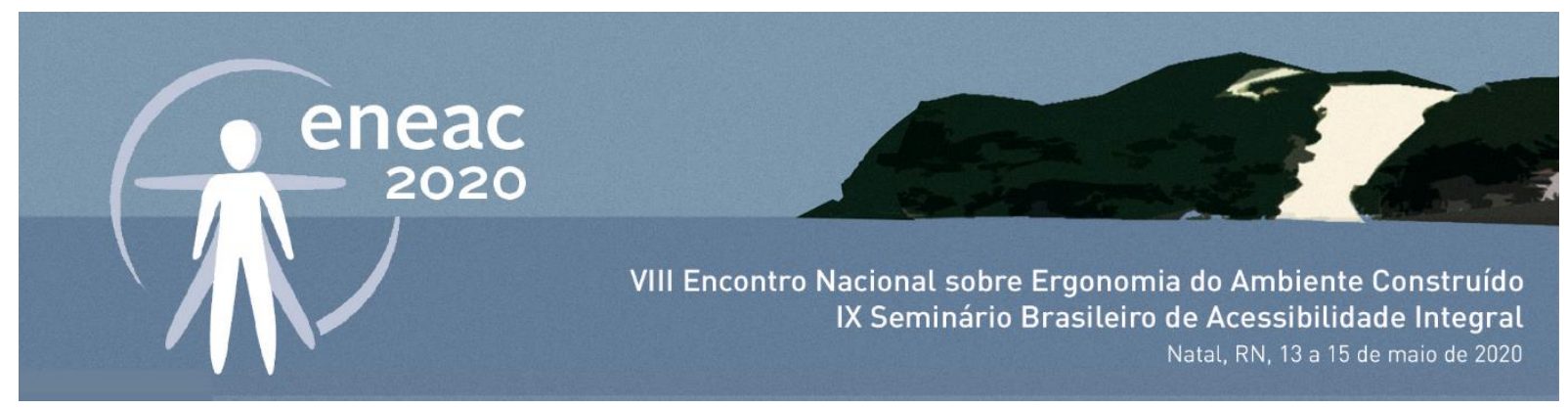

6. Desde o acesso aos banheiros observa-se também um amplo campo de visão para o pátio e corredores laterais, configurando como espaços de fácil identificação, apesar de, diretamente da entrada principal, haver uma certa dificuldade de visualização.

\section{CONCLUSÕES}

A partir das informações e resultados obtidos com a aplicação do método da VGA nesta pesquisa, foi possível encontrar respostas para a questão apontada ao final da introdução. É aceitável afirmar que a utilização do programa Depthmap para a elaboração dos grafos de conectividade e isovistas é uma ferramenta útil, empregada para a identificação das principais questões relacionadas à acessibilidade no ambiente escolar. A partir da interpretação dos resultados ficou claro que essa ferramenta pode auxiliar efetivamente na identificação de problemas e contribuir na proposição de melhores soluções configuracionais do espaço, a fim de gerar um ambiente no qual o aluno, principalmente aquele com algum tipo de deficiência física, possa locomover-se de modo autônomo e intuitivo, prevendo cenários projetuais inclusivos antes de serem construídas as propostas (potencial redução de custos e assertividade da proposta).

Nesse sentido, na perspectiva da educação inclusiva, para que o aluno possa ter acesso às estratégias de inclusão escolar praticadas, é necessário que o ambiente construído esteja adequado às suas reais necessidade espaciais, pois de nada adianta uma vasta política e ações visando a inclusão se o espaço não contribuir, constituído por barreiras e entraves à locomoção. Logo, sabendo-se que a acessibilidade físico-espacial está diretamente ligada ao sucesso de ações voltadas à educação inclusiva, a VGA pode se mostrar como uma importante estratégia na promoção de projetos para a acessibilidade físico-espacial, e consequentemente na proposição de estratégias para a educação inclusiva.

Logo, a partir da VGA é possível identificar os principais obstáculos e entraves a serem resolvidos. Os grafos podem contribuir para o melhor posicionamento de rampas e escadas, e para identificar locais que necessitam maior campo visual a fim de possibilitar um deslocamento mais seguro e autônomo.

As possíveis contribuições não se restringem a reformas, podendo auxiliar em projetos para novas escolas, ajudando a resolver, por exemplo, questões que surgem ainda na fase do partido arquitetônico.

Em relação à escola aqui analisada, notou-se que essa possui grande conectividade e facilidade de entendimento visual, o que contribui positivamente no acesso e locomoção com autonomia. Entretanto, passando ao campo físico, considerando barreiras à locomoção, problemas foram encontrados com a aplicação dos grafos. Assim, o uso da ferramenta pode contribuir na proposição de melhorias, solucionando esses problemas em futuras reformas.

Por fim, fica clara a possibilidade de aplicação da VGA como ferramenta projetual auxiliar nas questões voltadas à acessibilidade físico-espacial. Essa ferramenta pode contribuir positivamente na política de expansão do Programa Escolas Cidadãs Integrais, possibilitando espaços mais inclusivos. 


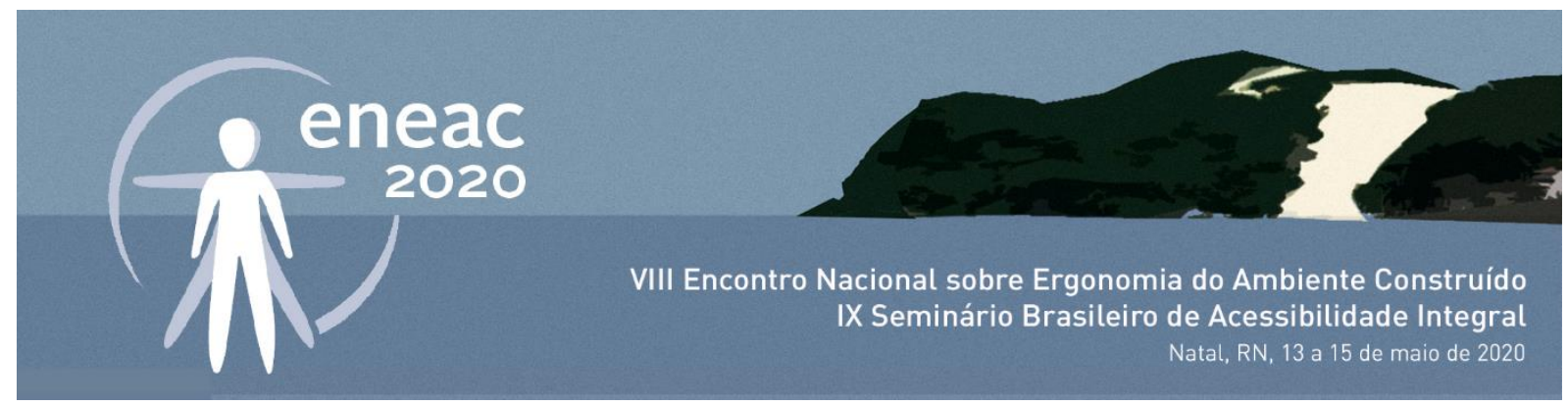

\section{REFERÊNCIAS}

ABNT. ASSOCIAÇÃO BRASILEIRA DE NORMAS TÉCNICAS. NBR 9050: Acessibilidade a edificações, mobiliário, espaços e equipamentos urbanos. Rio de Janeiro. 2015.

ARIAS, C. R. A arquitetura como instrumento do projeto inclusivo: percepção do surdocego. Dissertação de mestrado. Faculdade de Engenharia Civil, Arquitetura e Urbanismo, Departamento de Arquitetura e Urbanismo, Departamento de Arquitetura e Construção, Universidade Estadual de Campinas, UNICAMP, 2008.

BENEDIKT, M. L. To Take Hold of Space: Isovists and Isovist Fields. Environment and Planning B, v.6, p. 47-65, 1979.

BENVEGNú, E. M. Acessibilidade espacial requisito para uma escola inclusiva: Estudo de caso - Escolas Municipais de Florianópolis. Florianópolis, 9 de outubro de 2009. 188p. Dissertação (Mestrado em Arquitetura e Urbanismo) - Programa de Pós-Graduação, UFSC, 2009. BRASIL. Ministério Público Federal: Fundação Procurador Pedro Jorge de Melo e Silva. O Acesso de Alunos com Deficiência às Escolas e Classes Comuns da Rede Regular. 2a ed. rev. e atualizada. Brasília: Procuradoria Federal dos Direitos do Cidadão, 2004.

IBGE. Instituto Brasileiro de Geografia e Estatística. Censo Demográfico 2010: Informações por município. Disponível em < https://censo2010.ibge.gov.br/apps/mapa/ > Acesso em 28 de outubro de 2019.

IBGE. Instituto Brasileiro de Geografia e Estatística. IBGE CIDADES: Informações por município. Disponível em < https://cidades.ibge.gov.br/ > Acesso em 28 de outubro de 2019.

CALADO, G. C. Acessibilidade no ambiente escolar: Reflexões com base no estudo de duas escolas municipais de Natal - RN. Dissertação de mestrado. UFRN, Natal, 2006.

CARLETTO, A. C.; CAMBIAGHI, S. Desenho universal: um conceito para todos. Realização: Mara Gabrilli. 2007.

DELGADO, U. S.; MARTíNES, F. G. F.; FLORES, M. P. S.; LECHUGA, A. M. Q. Inclusión Educativa en América Latina, una mirada más allá de la educación especial. ConCiencia EPG -Volumen I - № 1 Junio, 2016

ELALI, G. A; SÁ, D. C. de. Pensando mobilidade, projetando acessibilidade. II ENANPARQ, Natal, 18 a 21 de setembro de 2012.

GEHL, J. Cidades Para Pessoas. Tradução: Anita Di Marco. 2ª edição São Paulo, Perspectiva, 2013.

GURGEL, A. P. C. "Diálogos entre Lina Bo Bardi e Julienne Hanson: a produção arquitetônica residencial modernista brasileira sob a ótica da sintaxe espacial". Dearq, no. 23 (2018): 36-45.

HILLIER, B.; HANSON, J. The reasoning art: or, the need for an analytical theory of architecture. In: 1st International Space Syntax Symposium. London, England, 1997.

MANTOAN, M. T. E. Inclusão Escolar: O que é? Por que? Como fazer? 1. ed. São Paulo: Moderna, 2003. 95p.

MANTOAN, M. T. E. (orgs.). O desafio das diferenças nas escolas. Petrópolis, RJ: Vozes, 2008. 152p.

STEINFELD, E. What is Universal Design? Steinfeld and Maisel, 2012. Disponível em: www.universaldesign.com. Acesso em 09 de novembro de 2019.

TURNER, A.; DOXA, M.; O'SULLIVAN, D.; PENN, A. From Isovists to Visibility Graphs: A Methodology for the Analysis of Architectural Space". Environment and Planning B, n.28, v.1, p.103-121, 2001. 